\title{
Expert Panel Statement on Laparoscopic Living Donor Hepatectomy
}

\author{
Ho-Seong Han $^{\text {a }}$ Jai Young Cho ${ }^{a}$ Hironori Kaneko ${ }^{e}$ Go Wakabayashi ${ }^{f}$

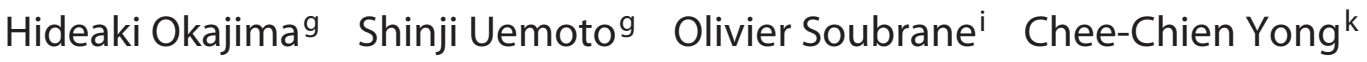 \\ Chao-Long Chenk ${ }^{k}$ Tan To Cheung ${ }^{\text {n }}$ Giulio Belli ${ }^{\circ}$ Shoji Kubo ${ }^{h}$ \\ Yao-Ming Wul Kuo-Hsin Chen ${ }^{m}$ Roberto I. Troisi ${ }^{p}$ Choon Hyuck David Kwon ${ }^{b}$ \\ Kyung-Suk Suh ${ }^{c}$ Arvinder S. Soin ${ }^{q}$ Ki-Hun Kim ${ }^{d}$ Daniel Cherqui ${ }^{j}$ \\ a Seoul National University Bundang Hospital, Seongnam, ${ }^{\mathrm{b}}$ Samsung Medical Center, and 'Seoul National University \\ Hospital, and d Asan Medical Center, Seoul, South Korea; ${ }^{\mathrm{e}}$ Toho University, Tokyo, ${ }^{\mathrm{f}}$ Ageo Central General Hospital, \\ Ageo, ${ }^{9}$ Kyoto University, Kyoto, and h Osaka City University, Osaka, Japan; 'Beaujon Hospital, Paris, and ${ }^{\mathrm{j} P a u l}$ Brousse \\ Hospital, Villejuif, France; 'Chang Gung Memorial Hospital, Kaohsiung, 'National Taiwan University Hospital, \\ Taipei, and ${ }^{m}$ Far Eastern Memorial Hospital, New Taipei City, Taiwan; ${ }^{n}$ The University of Hong Kong, Hong Kong,

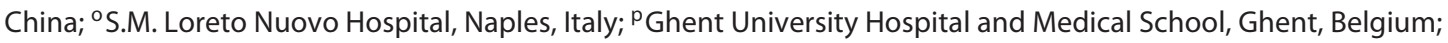 \\ qMedanta Institute, Gurgaon, India
}

\section{Keywords}

Minimal invasive surgery · Liver transplantation ·

Consensus · Recommendation

\begin{abstract}
Background: With improvements in living donor liver transplantation (LDLT) techniques and the increased experience of surgeons in laparoscopic major liver resection, laparoscopic donor hepatectomy is performed increasingly. Therefore, expert opinion on this procedure is required. Objective: The study aimed to report the current status and summarize the expert opinion on laparoscopic donor hepatectomy. Methods: An expert consensus meeting was held on September 8, 2016, in Seoul, Korea. Results: Laparoscopic donor left lateral sectionectomy could be considered the standard practice in pediatric LDLT. In adult LDLT, laparoscopy-assisted donor hepatectomy or left hepatectomy is potentially the next need, requiring more evidence for becoming standard practice. Laparoscopic donor right hepatecto-
\end{abstract}

\section{KARGER}

(c) 2017 S. Karger AG, Basel

E-Mail karger@karger.com

www.karger.com/dsu my is still in the developmental stage, and more supporting evidence is required. Waving the cost consideration, the robotic approach could be a valid alternative for the suitable approaches of laparoscopy. Conclusions: Laparoscopic donor hepatectomy is increasing its role in both pediatric and adult LDLT. However, for major donor hepatectomy, more evidence is needed.

(c) 2017 S. Karger AG, Basel

\section{Introduction}

Living donor liver transplantation (LDLT) is one of the common forms of liver transplantation, especially in countries where deceased donors are scarce. Since the

This meeting was held during the 26th World Congress of the International Association of Surgeons, Gastroenterologists and Oncologists (IASGO 2016) in Seoul, 2016. 
first successful LDLT of a left lateral section graft in 1989 [1], the most important development has been the extension of LDLT to adults. Consequently, right lobe LDLT has been introduced and is widely performed [2]. Although different surgical approaches are used, open living donation always requires a large abdominal incision. The consequent huge scar, together with postoperative pain, a long hospital stay, and a long period of recovery, have caused hesitation among potential donors, especially young donors [3].

In parallel with LDLT, laparoscopic liver resection (LLR) has evolved dramatically with the accumulation of experience, better visualization of the operative field with high-quality imaging laparoscopes, and the use of specialized laparoscopic instruments for transecting the liver parenchyma $[4,5]$. Since its initial application to benign disease, the indications for laparoscopic LLR have been extended to include malignant diseases, such as hepatocellular carcinoma and colorectal liver metastasis. At the first consensus meeting to address LLR, laparoscopic left lateral sectionectomy (LLS) was stated to be the standard treatment option [6]. However, laparoscopic major liver resection, such as right or left hemihepatectomy, has recently been performed more frequently $[7,8]$, and the outcomes for malignant tumor are reported to be similar to those achieved with open surgery [9].

With the increasing demand for living donor right hepatectomy and our accumulating experience with LLR, minimally invasive surgery has been cautiously applied to living donor hepatectomy. First, laparoscopic donor hepatectomy (left lateral section graft) was performed for LDLT in children [3], and then hand-assisted [10] or laparoscopy-assisted living donor right hepatectomy $[11,12]$ was performed in adult donors. However, a hybrid technique that includes hand-assisted or laparoscopy-assisted living donor right hepatectomy still requires a significant abdominal incision and diminishes the advantages of a totally laparoscopic procedure. The residual abdominal scar is also too large to meet the demands of young donors. However, with extensive experience of LLR and confidence that donor safety is ensured, total laparoscopic donor hepatectomy has been reported by several experts [13-15].

Here, we report an expert panel statement for laparoscopic living donor hepatectomy compiled during the 26th World Congress of the International Association of Surgeons, Gastroenterologists and Oncologists (IASGO 2016) in Seoul, 2016.

Expert Panel Statement on Laparoscopic

Living Donor Hepatectomy

\section{Methods}

The 17-member panel was invited to participate based upon their achievements and experience in the fields of both LLR and liver transplantation. The panel included surgeons who had already performed laparoscopic donor hepatectomy, surgeons who had performed LLR without laparoscopic donor hepatectomy, and those who had performed LDLT without laparoscopic surgery. The meeting was held on September 8, 2016, in Seoul, Korea. About 100 attendees were present from all over the world. The panel members were asked to present previously assigned aspects of laparoscopic donor surgery, ranging from left-side to right-side donor hepatectomy. The recommendations of the Second International Consensus Conference on LLR were also taken into consideration. Two chairpersons moderated a discussion of the controversial points in each session. The presentations were accompanied by designated panel discussions, and feedback from the audience was collected as base data. After the meeting, an interim manuscript was prepared, circulated, and edited. All the listed authors then reviewed and agreed to the content of the present document, including the summaries.

\section{Results}

\section{Recommendations of the Second International}

Consensus Conference [16]

With improvements in surgical techniques, the development of convenient energy devices, and conceptual changes in liver resection to a caudal approach, LLR has passed a tipping point, although strong evidence is still required for international registration and randomized controlled trials. Laparoscopic donor hepatectomy is not the most difficult operation to perform because the transection of the complete normal liver parenchyma and the preoperative anatomy are well understood. Laparoscopic donor hepatectomy requires an extremely careful and meticulous technique because small breaks in the technique may jeopardize donor safety, which is of utmost priority. Several retrospective studies of pediatric LDLT compared the outcomes of open and laparoscopic donor hepatectomy (usually LLS) and demonstrated that in highly specialized centers, minimally invasive surgery in terms of patient safety did not differ from the open procedure. The procedure was classified as IDEAL $2 \mathrm{~b}$ meaning that considerable preliminary data supporting the safety of the procedure have been presented, but its novelty should suggest caution. Conversely, in adult-toadult LDLT, laparoscopic donor hepatectomy (usually right hepatectomy) was classified as IDEAL 2a which corresponds to the earliest phase of development, then with the highest degree of risk because of the novelty of 
the procedure. Therefore, this stage needs for institutional ethical approval to perform the procedure and a reporting registry is required.

\section{Summary}

Laparoscopic donor hepatectomy is recommended in both high volume LLR and LDLT centers.

\section{Laparoscopy-Assisted Living Donor Hepatectomy}

Although pure laparoscopy is the most commonly used technique worldwide, there are geographical differences in its use, and many centers use laparoscopy-assisted donor surgery, including hand-assisted laparoscopic surgery and a hybrid technique in selected cases. For surgeons who have insufficient experience of pure laparoscopic major hepatectomy, laparoscopy-assisted donor surgery is recommended [17, 18]. Laparoscopy-assisted donor surgery has many advantages including the use of the hanging maneuver and an open stapler for cutting the hepatic vein. It can be used to manage any intraoperative difficulties that are encountered, and theoretically reduce the frequency of conversion to a full open incision. Koffron et al. [11] suggested that laparoscopy-assisted living donor hepatectomy for a right lobe graft procurement is the best option because anatomical variations may not be problematic when a hand-assisted/extraction incision is performed, as for the open technique, and the parenchyma is transected with direct vision and with the standard instruments used in conventional open hepatectomy.

\section{Summary}

Laparoscopy-assisted donor hepatectomy could be a good option during the transition from open to total laparoscopic donor hepatectomy.

\section{Robotic Donor Hepatectomy}

Robotic donor hepatectomy has also been reported $[19,20]$. The amplified $3 \mathrm{D}$ view and steady instrument movement of the robotic procedure ensures meticulous dissection of the deep parenchyma and results in similar blood loss to that lost during the open procedure. Compared with the open group, the robotic group required less postoperative pain control and tended to have earlier ambulation after their operation. The patients in the robotic group also tended to return to their daily activities earlier than those in the open group, although the differ- ences were only statistically significant for work/school and sexual activities [19]. The outcomes of robotic and laparoscopic donor hepatectomy were similar, but the cost of robotic surgery is still high. However, as the number of degrees of freedom is greater in robotic surgery, it may be more convenient than laparoscopic surgery for surgeons with insufficient experience of laparoscopic surgery. Robotic donor hepatectomy would be performed more frequently if the cost will be reasonable.

\section{Summary}

Despite the higher medical costs associated with the robotic platform than with the open approach, robotic donor hepatectomy is an alternative option for pure minimally invasive liver donor surgery.

\section{Laparoscopic Donor Left-Side Hepatectomy}

Theoretically, live donors will probably benefit most from minimally invasive surgery because laparoscopic organ procurement ensures an excellent cosmetic outcome, reduced postoperative pain, and early recovery [21]. Laparoscopic LLS for LDLT provides better conditions for pure laparoscopic surgery than does right hepatectomy, including better access, fewer anatomical variations, and easier mobilization. LLS for pediatric LDLT was first described in 2002 [3], and its safety and reproducibility have already been demonstrated [22], with a shift from innovation to development [23]. Moreover, laparoscopic LLS for pediatric LDLT has shown similar short-term outcomes as laparoscopic donor nephrectomy, suggesting that the laparoscopic approach should be considered the new standard practice [24]. However, for adult-to-adult LDLT, donor hepatectomy is required to harvest a large liver volume, such as the left or right lobe. Recently, the utility of indocyanine green near-infrared fluorescence cholangiography in visualizing the biliary ducts in laparoscopic livingdonor left hepatectomy and donor right hepatectomy has been demonstrated [25]. Despite that, the longer operation time, difficulty in managing bleeding from the hepatic vein or inferior vena cava, and injury to the graft during right liver mobilization make laparoscopic right side donor hepatectomy still controversial. Therefore, pure laparoscopic left liver graft is preferentially used, to reduce donor morbidity, with functional advantages in adult-toadult LDLT $[26,27]$. Indeed, the left lobe is featured by few variations in the vascular and biliary anatomy, which offers an easier vascular control, needs a minimal mobilization, and the related learning curve is short [28]. 


\section{Summary}

Experts agreed that laparoscopic donor LLS should be considered a standard practice for pediatric LDLT, while for adult LDLT this could be the case in the near future of laparoscopic donor left hepatectomy.

\section{Laparoscopic Donor Right Hepatectomy}

All panel members agreed that laparoscopic donor right hepatectomy is still innovative and in the developmental stage, and can only be recommended for performance by surgeons experienced in both LLR and LDLT. They also suggested that donor safety is most important, although the surgeon's efforts to improve the donor's quality of life are appreciated. Although successful laparoscopic donor right hepatectomy in donors with bile duct trifurcation has been reported [29], the donor selection criteria must be strict. Therefore, it was recommended that laparoscopic donor right hepatectomy be avoided when the anatomy is very complicated. Some experts recommended that the donor indications for laparoscopic right hepatectomy should be a graft-to-recipient weight ratio $>1.0$, a remnant liver volume $>35 \%$, and a normal bile duct anatomy and portal vein. They also recommended that the procedure might be indicated for some more complicated types of anatomy if the surgeon has sufficient experience, as for open surgery. It is difficult to reach a consensus on the details of the technique because this operation is still developing and individual preferences differ markedly. However, the technical aspects of bile duct cutting have been widely discussed because experts consider that bile duct cutting is one of the most difficult aspects of this surgery. Intraoperative cholangiograms before and after cutting the bile duct are frequently used to avoid bile duct problems, and indocyanine green fluorescent imaging was suggested to better visualize the anatomy of the bile duct. Surgeons from Asia also recommended 3D videoscopy because it allows better visualization of the anatomy and blood vessels. Most panel members considered that laparoscopic donor right hepatectomy will be the future standard procedure for donor surgery, but they unanimously agreed that more evidence is required.

\section{Summary}

Laparoscopy donor right hepatectomy is still a developing technique. The panel recommended that it only be performed by highly proficient surgeons with extensive experience in both LDLT and LLR. More data and an international registry are required for future standardization.

\section{Conclusions}

Laparoscopic donor LLS has been well validated and is considered the standard technique for donor liver procurement in experienced centers. Other forms of laparoscopic hemihepatectomy for left or right lobe graft procurement are technically feasible for practitioners experienced in both LLR and LDLT. However, they are unsuitable for wide application because the evidence supporting them is still inadequate. In particular, it is necessary to set up an international registry and hold a consensus meeting before laparoscopic donor right hepatectomy can be widely accepted.

\section{Disclosure Statement}

The authors have no conflicts of interest to declare.

\section{References}

1 Strong RW, Lynch SV, Ong TH, Matsunami H, Koido Y, Balderson GA: Successful liver transplantation from a living donor to her son. N Engl J Med 1990;322:1505-1507.

2 Lo CM, Fan ST, Liu CL, Yong BH, Wong Y, Lau GK, Lai CL, Ng IO, Wong J: Lessons learned from one hundred right lobe living donor liver transplants. Ann Surg 2004;240: 151-158.

3 Cherqui D, Soubrane O, Husson E, Barshasz E, Vignaux $\mathrm{O}$, Ghimouz $\mathrm{M}$, Branchereau $\mathrm{S}$, Chardot C, Gauthier F, Fagniez PL, Houssin D: Laparoscopic living donor hepatectomy for liver transplantation in children. Lancet 2002;359:392-396.

4 Han HS, Cho JY, Yoon YS: Techniques for performing laparoscopic liver resection in various hepatic locations. J Hepatobiliary Pancreat Surg 2009;16:427-432.

5 Guro H, Cho JY, Han HS, Yoon YS, Choi Y, Periyasamy M: Current status of laparoscopic liver resection for hepatocellular carcinoma. Clin Mol Hepatol 2016;22:212-218.

6 Buell JF, Cherqui D, Geller DA, O'Rourke N, Iannitti D, Dagher I, Koffron AJ, Thomas M, Gayet B, Han HS, Wakabayashi G, Belli G,
Kaneko H, Ker CG, Scatton O, Laurent A, Abdalla EK, Chaudhury P, Dutson E, Gamblin C, D'Angelica M, Nagorney D, Testa G, Labow D, Manas D, Poon RT, Nelson H, Martin R, Clary B, Pinson WC, Martinie J, Vauthey JN, Goldstein R, Roayaie S, Barlet D, Espat J, Abecassis M, Rees M, Fong Y, McMasters KM, Broelsch C, Busuttil R, Belghiti J, Strasberg S, Chari RS; World Consensus Conference on Laparoscopic Surgery: The international position on laparoscopic liver surgery: the louisville statement, 2008. Ann Surg 2009;250:825-830.
Expert Panel Statement on Laparoscopic Living Donor Hepatectomy 
7 Park JS, Han HS, Hwang DW, Yoon YS, Cho JY, Koh YS, Kwon CH, Kim KS, Kim SB, Kim YH, Kim HC, Chu CW, Lee DS, Kim HJ, Park SJ, Han SS, Song TJ, Ahn YJ, Yoo YK, Yu HC, Yoon DS, Lee MK, Lee HK, Min SK, Jeong CY, Hong SC, Choi IS, Hur KY: Current status of laparoscopic liver resection in korea. J Korean Med Sci 2012;27:767-771.

8 Hwang DW, Han HS, Yoon YS, Cho JY, Kwon Y, Kim JH, Park JS, Yoon DS, Choi IS, Ahn KS, Kim YH, Kang KJ, Kim YH, Roh YH, Chu CW, Kim HC, Kang CM, Choi GH, Choi JS, Kim KS, Lee WJ, Yun SS, Kim HJ, Min SK, Lee HK, Song IS, Chun KS, Cho EH, Han SS, Park SJ: Laparoscopic major liver resection in Korea: a multicenter study. J Hepatobiliary Pancreat Sci 2013;20:125-130.

9 Han HS, Shehta A, Ahn S, Yoon YS, Cho JY, Choi Y: Laparoscopic versus open liver resection for hepatocellular carcinoma: casematched study with propensity score matching. J Hepatol 2015;63:643-650.

10 Nitta H, Sasaki A, Otsuka Y, Tsuchiya M, Kaneko H, Wakabayashi G: Impact of hybrid techniques on laparoscopic major hepatectomies. J Hepatobiliary Pancreat Sci 2013;20: 111-113.

11 Koffron AJ, Kung R, Baker T, Fryer J, Clark L, Abecassis M: Laparoscopic-assisted right lobe donor hepatectomy. Am J Transplant 2006;6: 2522-2525.

12 Suh KS, Yi NJ, Kim J, Shin WY, Lee HW, Han HS, Lee KU: Laparoscopic hepatectomy for a modified right graft in adult-to-adult living donor liver transplantation. Transplant Proc 2008;40:3529-3531.

13 Han HS, Yoon YS, Cho JY: World first laparoscopic donor right hepaectomy. THE DONG-A ILBO 2010;A27.

14 Soubrane O, Perdigao Cotta F, Scatton O: Pure laparoscopic right hepatectomy in a living donor. Am J Transplant 2013;13:2467-2471.

15 Rotellar F, Pardo F, Benito A, Marti-Cruchaga P, Zozaya G, Lopez L, Hidalgo F, Sangro B, Herrero I: Totally laparoscopic right-lobe hepatectomy for adult living donor liver transplantation: useful strategies to enhance safety. Am J Transplant 2013;13:3269-3273.

16 Wakabayashi G, Cherqui D, Geller DA, Buell JF, Kaneko H, Han HS, Asbun H, O'Rourke N, Tanabe M, Koffron AJ, Tsung A, Soubrane O, Machado MA, Gayet B, Troisi RI, Pessaux P, Van Dam RM, Scatton O, Abu Hilal M, Belli G, Kwon CH, Edwin B, Choi GH, Aldrighetti LA, Cai X, Cleary S, Chen KH, Schon MR, Sugioka A, Tang CN, Herman P, Pekolj J, Chen XP, Dagher I, Jarnagin W, Yamamoto M, Strong R, Jagannath P, Lo CM, Clavien PA, Kokudo N, Barkun J, Strasberg SM: Recommendations for laparoscopic liver resection: a report from the second international consensus conference held in morioka. Ann Surg 2015;261:619-629.

17 Koffron AJ, Kung RD, Auffenberg GB, Abecassis MM: Laparoscopic liver surgery for everyone: the hybrid method. Surgery $2007 ; 142$ : 463-468; discussion 468.e461-e462.

18 Buell JF, Thomas MT, Rudich S, Marvin M, Nagubandi R, Ravindra KV, Brock G, McMasters KM: Experience with more than 500 minimally invasive hepatic procedures. Ann Surg 2008;248:475-486.

19 Chen PD, Wu CY, Hu RH, Ho CM, Lee PH, Lai HS, Lin MT, Wu YM: Robotic liver donor right hepatectomy: a pure, minimally invasive approach. Liver Transpl 2016;22:1509-1518.

20 Giulianotti PC, Tzvetanov I, Jeon H, Bianco F, Spaggiari M, Oberholzer J, Benedetti E: Robot-assisted right lobe donor hepatectomy. Transpl Int 2012;25:e5-e9.

21 Bekheit M, Khafagy PA, Bucur P, Katri K, Elgendi A, Abdel-Salam WN, Vibert E, El-Kayal el-S: Donor safety in live donor laparoscopic liver procurement: Systematic review and meta-analysis. Surg Endosc 2015;29:30473064.

22 Soubrane O, Cherqui D, Scatton O, Stenard F, Bernard D, Branchereau S, Martelli H, Gauthier F: Laparoscopic left lateral sectionectomy in living donors: Safety and reproducibility of the technique in a single center. Ann Surg 2006;244:815-820.

23 Scatton O, Katsanos G, Boillot O, Goumard C, Bernard D, Stenard F, Perdigao F, Soubrane O: Pure laparoscopic left lateral sectionectomy in living donors: from innovation to development in France. Ann Surg 2015;261:506-512.

24 Soubrane O, de Rougemont O, Kim KH, Samstein B, Mamode N, Boillot O, Troisi RI, Scatton O, Cauchy F, Lee SG, Griesemer A, Ahmed Z, Clavien PA, Cherqui D: Laparoscopic living donor left lateral sectionectomy: a new standard practice for donor hepatectomy. Ann Surg 2015;262:757-761; discussion 761-753.

25 Tomassini F, Scarinci A, Elsheik Y, Scuderi V, Broering D, Troisi RI: Indocyanine green near-infrared fluorescence in pure laparoscopic living donor hepatectomy: a reliable road map for intra-hepatic ducts? Acta Chir Belg 2015;115:2-7.

26 Troisi RI, Wojcicki M, Tomassini F, Houtmeyers P, Vanlander A, Berrevoet F, Smeets P, Van Vlierberghe H, Rogiers X: Pure laparoscopic full-left living donor hepatectomy for calculated small-for-size ldlt in adults: proof of concept. Am J Transplant 2013;13: 2472-2478.

27 Samstein B, Griesemer A, Cherqui D, Mansour T, Pisa J, Yegiants A, Fox AN, Guarrera JV, Kato T, Halazun KJ, Emond J: Fully laparoscopic left-sided donor hepatectomy is safe and associated with shorter hospital stay and earlier return to work: a comparative study. Liver Transpl 2015;21:768-773.

28 Brustia R, Komatsu S, Goumard C, Bernard $\mathrm{D}$, Soubrane O, Scatton O: From the left to the right: 13-year experience in laparoscopic living donor liver transplantation. Updates Surg 2015;67:193-200.

29 Chen KH, Huang CC, Siow TF, Chio UC, Chen SD, Chen YD, Lin TC, Huang SY, Wu JM, Jeng KS: Totally laparoscopic living donor right hepatectomy in a donor with trifurcation of bile duct. Asian J Surg 2016;39:51-55. 